\title{
Dechlorination and destruction of 2,4,6-trichlorophenol and pentachlorophenol using hydrogen peroxide as the oxidant catalyzed by molybdate ions under basic condition
}

\author{
Chao Tai, Guibin Jiang * \\ Key Laboratory of Environmental Chemistry and Ecotoxicology, Research Center for Eco-Environmental Sciences, \\ Chinese Academy of Sciences, P.O. Box 2871, Beijing 100085, China
}

Received 31 May 2004; received in revised form 7 October 2004; accepted 19 October 2004

\begin{abstract}
The dechlorination and destruction of 2,4,6-trichlorophenol (TCP) and pentachlorophenol (PCP) under basic condition using hydrogen peroxide as the oxidant catalyzed by molybdate ions have been studied. Under ambient conditions of temperature and pressure, more than $95 \%$ of millimolar solutions of TCP and PCP can be converted to $\mathrm{CO}_{2}$ and $\mathrm{CO}$, chlorinated and nonchlorinated carboxylic acid in $40 \mathrm{~min}$. Up to 2.4 chloride ions per TCP and 3.5 chloride ions per PCP were released. TOC measurements indicated that $18 \%$ and $11 \%$ of the carbon was mineralized for TCP and PCP respectively after an hour of reaction. The results of ESR measurements suggested that the reaction possibly proceeded via the pathway with singlet oxygen.
\end{abstract}

(C) 2004 Elsevier Ltd. All rights reserved.

Keywords: Molybdate ions; Hydrogen peroxide; Singlet oxygen; Destruction; Dechlorination; 2,4,6-Trichlorophenol; Pentachlorophenol

\section{Introduction}

Highly chlorinated phenol derivatives, such as 2,4,6trichlorophenol (TCP) and pentachlorophenol (PCP), have been commonly used as the wood preservative, pesticide, herbicide, and defoliant since the early 1930s. They can be found in the chlorine-disinfected drinking water, river water, sediments, and landfill leachate with high concentration (Ramamoorthy, 1997). They have

\footnotetext{
* Corresponding author. Tel.: +86 10 62849179/62923566; fax: +861062923563 .

E-mail address: gbjiang@mail.rcees.ac.cn (G. Jiang).
}

been recognized as the priority pollutants in the United States as well as in China (Xia and Zhang, 1990; USEPA, 1991). Due to their high toxicity, carcinogenic properties, and persistence in the environment, much attention has been focused on their presence in and removal from the environment (Magar et al., 1999; Piringer and Bhattacharya, 1999; Fukushima and Tatsumi, 2001; Ye and Shen, 2004).

In the past decades, hydrogen peroxide is increasingly favoured as an environmentally acceptable oxidant for the treatment of wastewater. Many systems have been developed for the removal of organic compounds from water using hydrogen peroxide as the oxidant activated by various catalyst (Klibanov and Tu, 1983; Sorokin et al., 1995; Kwon et al., 1999). Among them, 
the Fenton reaction $\left(\mathrm{Fe}^{2+} / \mathrm{H}_{2} \mathrm{O}_{2}\right)$ has been proved to be an effective as well as environmentally benign method, in which the organic pollutant is degraded by the reactive oxygen species such as hydroxyl radical and hydroperoxyl radical generated from $\mathrm{H}_{2} \mathrm{O}_{2}-\mathrm{Fe}^{2+} / \mathrm{Fe}^{3+}$ reaction (Fukushima and Tatsumi, 2001; Gallard and De Laat, 2001; Kang et al., 2002; Lee et al., 2003). However, the reaction rate drops off sharply above and below the optimum $\mathrm{pH}$ of 2.8-4 (Sun and Pignatello, 1992; Chu and Law, 2003; Cheng et al., 2004). The narrow effective $\mathrm{pH}$ range limits the utility of $\mathrm{Fe} / \mathrm{H}_{2} \mathrm{O}_{2}$ for treating wastewater of the $\mathrm{pH}$ above 8 . Many modifications have been applied in order to increase the $\mathrm{pH}$ range. This has led to a great variety of ligated iron complexes in combination with hydrogen peroxide or even with other transition metals, such as $\mathrm{Mn}(\mathrm{II}), \mathrm{Cu}(\mathrm{II})$ and $\mathrm{Co}(\mathrm{II})$, for the wastewater treatment (Sun and Pignatello, 1993; Nerud et al., 2001; Salem, 2001; Verma et al., 2003; Gabriel et al., 2004). In these systems, the hydroxyl radicals are thought to play an important role in the degradation of the pollutants.

In this study, a new system for the dechlorination and destruction of TCP and PCP under basic condition using hydrogen peroxide as the oxidant catalyzed by molybdate ions was described. The major goals of this study were to examine the catalytic activity of $\mathrm{MoO}_{4}^{2-} / \mathrm{H}_{2} \mathrm{O}_{2}$ system in the degradation and dechlorination of TCP and PCP; and to optimize the operating conditions by investigating the effect of $\mathrm{pH}$, temperature, and $\mathrm{MoO}_{4}^{2-}$ and $\mathrm{H}_{2} \mathrm{O}_{2}$ concentration.

\section{Materials and methods}

\subsection{Chemicals}

TCP and PCP were purchased from Acros and used without further purification. Triethylsulfonium hydroxide was obtained from Tokyo Kasi. 2,2,6,6-tetramethylpiperidine (TEMP) was purchased from Alfa Aesar. Sodium molybdate and hydrogen peroxide were purchased from the Beijing Chemical Reagent Corporation. The other reagents were all of analytical reagent grade. The water used in all experiments was purified with a Milli-Q water ion-exchange system to give a resistivity of $18.3 \mathrm{M} \Omega \mathrm{cm}$.

\subsection{Analytical methods}

The HPLC equipment used was an Agilent 1100LC including a BinPump and a VWD detector. The VWD detector was set at $254 \mathrm{~nm}$ wavelength. An Agilent Zorbax Eclipse $\mathrm{XDB}-\mathrm{C}_{18}$ column $(150 \times 4.6 \mathrm{~mm}$, particle size $5 \mu \mathrm{m}$ ) was used as analytical column. A mixture of acetonitrile and water $(60: 40, \mathrm{v} / \mathrm{v})$ was used as the mobile phase at a flow rate of $1.0 \mathrm{ml} \mathrm{min}{ }^{-1}$.
$\mathrm{Cl}^{-}$released during the TCP or PCP degradation was determined on a Shimadzu UV-3000 spectrophotometer by a modified mercury(II) thiocyanate method (Florence and Fanar, 1971). $0.2 \mathrm{ml}$ of the mixed solution was taken periodically and added into $1.0 \mathrm{ml} 0.375 \mathrm{M}$ ferric nitrate (in $5.25 \mathrm{M}$ perchloric acid). $0.5 \mathrm{ml}$ saturated mercuric thiocyanate in ethanol was then added, and the absorbance of the sample was measured after $5 \mathrm{~min}$ at $460 \mathrm{~nm}$. The chloride concentration on each sample was then determined from a linear calibration plot of chloride standards.

The final products of the degradation of TCP or PCP were identified as follows: the reaction mixture was evaporated under vacuum. The residue was dissolved in $3 \mathrm{M} \mathrm{HCl}$ to produce a $\mathrm{pH}<2$. The resulting solution was saturated with $\mathrm{NaCl}$ and extracted with diethyl ether $(3 \times 10 \mathrm{ml})$. The combined ether extracts were dried with anhydrous sodium sulfate and the ether was evaporated under vacuum. The residue was dissolved in methanol and treated with trimethylsulfonium hydroxide and analyzed by GC-MS.

Total organic carbon (TOC) measurements were carried out on an Apollo 9000 TOC Analyzer (TekmarDohrmann Co., USA). Electron spin resonance (ESR) measurements were carried out on a Bruker ESP 300E Electron Spin Resonance Spectrometer.

\subsection{The typical procedure}

A typical reaction mixture contained $1 \mathrm{mM}$ TCP or PCP, $2 \mathrm{mM}$ of sodium molybdate. Reaction medium was adjusted to $\mathrm{pH} 10$ with $\mathrm{NaHCO}_{3}$ and $\mathrm{NaOH}$ resulting a final volume of $5 \mathrm{ml}$. The reaction was initiated by addition of $0.15 \mathrm{ml} 0.8 \mathrm{M} \mathrm{H}_{2} \mathrm{O}_{2}$. Samples of $0.2 \mathrm{ml}$ taken at different reaction times were diluted to $5 \mathrm{ml}$ by $0.1 \mathrm{M}$ $\mathrm{H}_{3} \mathrm{PO}_{4}$ solution with a final $\mathrm{pH}$ of 5.1 , and the remaining TCP or PCP in the sample was quantified by HPLC.

\section{Results and discussion}

\subsection{Degradative behavior}

Fig. 1 shows the time course of the degradation of TCP and PCP. The results indicate that $\mathrm{H}_{2} \mathrm{O}_{2}$, as an environmentally safe oxidant, activated by $\mathrm{MoO}_{4}^{2-}$, can be used to oxidize TCP and PCP at room temperature efficiently. More than $95 \%$ of TCP and PCP conversion was observed within $40 \mathrm{~min}$. Control experiments with $\mathrm{H}_{2} \mathrm{O}_{2}$ in the absence of $\mathrm{MoO}_{4}^{2-}$ or with $\mathrm{MoO}_{4}^{2-}$ in the absence of $\mathrm{H}_{2} \mathrm{O}_{2}$ indicated no degradation of TCP and PCP.

The extent of degradation of TCP and PCP was also quantified by determination of both the residual TOC and inorganic chloride released. TOC measurements 


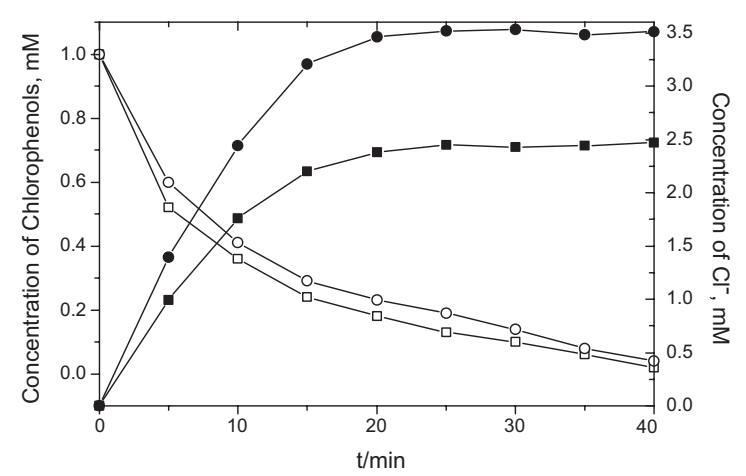

Fig. 1. Time course of the degradation of TCP and PCP. $[\mathrm{TCP}]_{0}$ or $\quad[\mathrm{PCP}]_{0}=1 \mathrm{mM}, \quad\left[\mathrm{MoO}_{4}^{2-}\right]_{0}=2 \mathrm{mM}, \quad\left[\mathrm{H}_{2} \mathrm{O}_{2}\right]_{0}=$ $24 \mathrm{mM}, \mathrm{pH}=10,25^{\circ} \mathrm{C}$. ( $\square$ ) Degradation of TCP; (O) degradation of PCP; $(\bullet)$ chloride ion release during the degradation of PCP; ( $\mathbf{\square})$ chloride ion release during the degradation of TCP.

indicated that $18 \%$ and $11 \%$ of the carbon was mineralized for TCP and PCP respectively after $1 \mathrm{~h}$ reaction. The results (Fig. 1) of chloride ion measurements show up to 2.4 chloride ions per TCP $(80 \%$ of the total chlorine) and 3.5 chloride ions per PCP ( $70 \%$ of the total chlorine) were released after $40 \mathrm{~min}$ reaction. Highly efficient dechlorination of the aromatic ring is very important because TCP and PCP can be converted to more biodegradable compounds by dechlorination.

2,6-Dichloro-1,4-benzonquinone (DCQ), as a stable oxidation product of TCP in the porphyrins or peroxidase catalytic system (Meunier and Sorokin, 1997), was not detected at the end of the catalytic reaction. The chloride ion release data and the absence of DCQ at the end of reaction suggested the aromatic ring was destroyed in the degradation of TCP and PCP. The products of the aromatic ring cleavage of TCP and PCP were identified by GC-MS after derivatization with trimethylsulfonium hydroxide (Sorokin et al., 1995). For TCP, oxalic acid $\mathbf{1}$, malonic acid $\mathbf{2}$, and fumaric acid $\mathbf{3}$, chloracrylic acid $\mathbf{4}$, were detected as their methyl esters. Besides compounds 1, 2, and 3, dichloracrylic acid 5 (Fig. 2) were also detected for PCP. GC-MS data of the products of the aromatic ring cleavage of TCP and PCP are shown in Table 1.

\subsection{Degradation mechanism}

Since hydrogen peroxide, catalyzed by some transition metal ions, can generate hydroxyl radicals, another experiment were designed to investigate whether hydroxyl radicals play an important role in the degradation of TCP and PCP by $\mathrm{MoO}_{4}^{2-} / \mathrm{H}_{2} \mathrm{O}_{2}$ system. Dimethyl sulphoxide, which can react with hydroxyl radicals to form formaldehyde, was used as the probe of hydroxyl radical (Klein et al., 1981). The formaldehyde was detected by HPLC after derivatization with dinitrophenylhydrazine (DNPH) (Oliva-Teles et al., 2002). Different from the Fenton reaction, there was not the corresponding peak of $\mathrm{HCHO}-\mathrm{DNPH}$ in the $\mathrm{MoO}_{4}^{2-} / \mathrm{H}_{2} \mathrm{O}_{2}$ system. These results indicate that hydroxyl radical does not play an important role in the degradation and dechlorination of TCP and PCP by the $\mathrm{MoO}_{4}^{2-} / \mathrm{H}_{2} \mathrm{O}_{2}$ system.<smiles>Oc1c(Cl)cc(Cl)cc1Cl</smiles>

$\mathrm{HOOC}-\mathrm{COOH}$<smiles>O=C(O)C=CC(=O)OO</smiles><smiles>Oc1c(Cl)c(Cl)c(Cl)c(Cl)c1Cl</smiles>
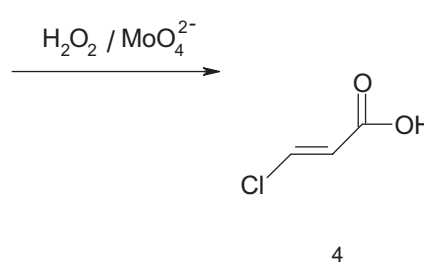<smiles>O=C(O)/C(Cl)=C/Cl</smiles>

Fig. 2. Products formed after $40 \mathrm{~min}$ of degradation of TCP and PCP.

Table 1

GC-MS data of the products of the aromatic ring cleavage of TCP and PCP

\begin{tabular}{lll}
\hline Compounds & Derivatized product & Mass spectrum $m / z$ (relative intensity) \\
\hline Oxalic acid & Oxalic acid, dimethyl ester & $59(100), 45(36.1), 29(22.9), 31(4.9), 30(3.1), 118(2.2)$ \\
Malonic acid & Malonic acid, dimethyl ester & $101(100), 59(98.8), 74(51.2), 42(36.4), 29(21.3), 43(19.3)$ \\
Fumaric acid & Fumaric acid, dimethyl ester & $113(100), 85(65.2), 59(37.2), 53(20), 114(21.2), 54(16.6)$ \\
Chloracrylic acid & Chloracrylic acid, methyl ester & $89(100), 91(33.9), 61(30.2), 85(29.4), 120(8.0), 53(5.3)$ \\
Dichloracrylic acid & Dichloracrylic acid, methyl ester & $119(100), 123(96), 125(66.2), 60(51.1), 97(39), 154(34.6)$ \\
\hline
\end{tabular}




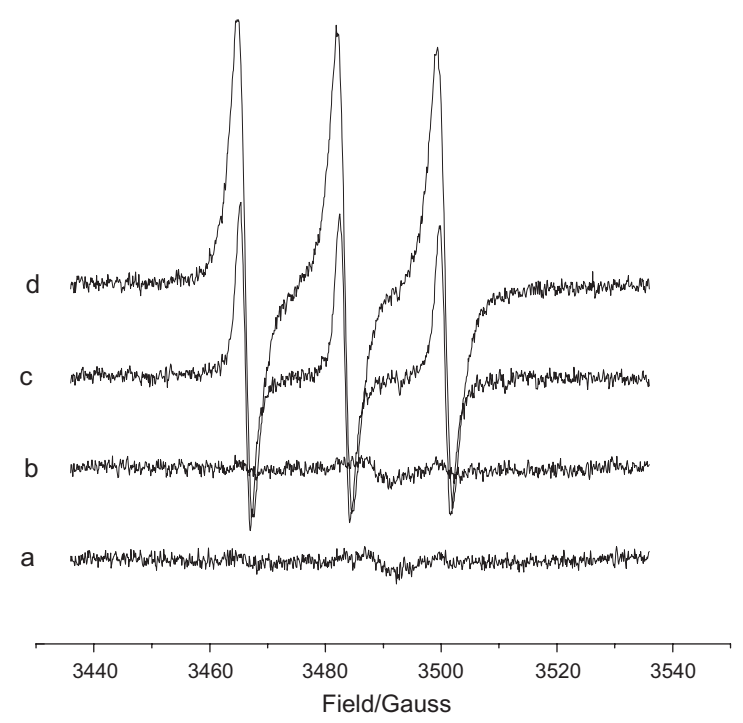

Fig. 3. ESR spectra of solutions under different conditions in the presence of $10 \mathrm{mmoll}^{-1}$ TEMP: (a) with $\mathrm{MoO}_{4}^{2-}$ in the absence of $\mathrm{H}_{2} \mathrm{O}_{2}$; (b) with $\mathrm{H}_{2} \mathrm{O}_{2}$ in the absence of $\mathrm{MoO}_{4}^{2-}$; (c) in presence of both $\mathrm{MoO}_{4}^{2-}$ and $\mathrm{H}_{2} \mathrm{O}_{2}$ for $5 \mathrm{~min}$; (d) in presence of both $\mathrm{MoO}_{4}^{2-}$ and $\mathrm{H}_{2} \mathrm{O}_{2}$ for $10 \mathrm{~min}$.

The degradation of TCP and PCP was extensively inhibited by the addition of aqueous sodium azide, a singlet oxygen scavenger (Almeida et al., 2003), to the solution. In our studies, the ESR technique was used to gain insight into the nature of radicals formed with TEMP as probe for the singlet oxygen. Fig. 3 illustrates the ESR spectra in different conditions. No signals of significant intensity were observed when the experiments were run with $\mathrm{H}_{2} \mathrm{O}_{2}$ in the absence of $\mathrm{MoO}_{4}^{2-}$ or with $\mathrm{MoO}_{4}^{2-}$ in the absence of $\mathrm{H}_{2} \mathrm{O}_{2}$. In presence of both $\mathrm{MoO}_{4}^{2-}$ and $\mathrm{H}_{2} \mathrm{O}_{2}$, the ESR signal displayed a triplet signal characteristic of 2,2,6,6-tetramethylpiperidinooxy (TEMPO) obtained by reaction with singlet oxygen (Fufezan et al., 2002). The results above suggested that the degradation of TCP and PCP by $\mathrm{MoO}_{4}^{2-} / \mathrm{H}_{2} \mathrm{O}_{2}$ system mainly proceeded via the pathway with singlet oxygen. The singlet oxygen was generated by the followed reactions (Aubry, 1988).

$$
\begin{aligned}
& 2 \mathrm{H}_{2} \mathrm{O}_{2}+\mathrm{MoO}_{4}^{2-} \rightleftarrows 2 \mathrm{H}_{2} \mathrm{O}+\mathrm{MoO}_{6}^{2-} \\
& \mathrm{MoO}_{6}^{2-} \rightarrow \mathrm{MoO}_{4}^{2-}+{ }^{1} \mathrm{O}_{2}
\end{aligned}
$$

\subsection{Effect of experimental conditions}

\subsubsection{Effect of $p H$}

The $\mathrm{pH}$ dependences of the degradation and dechlorination of TCP were studied. Sodium hydrogen carbonate, phosphoric acid and sodium hydroxide were chosen to adjust the $\mathrm{pH}$ in the range of $8-13$. Fig. 4 shows the

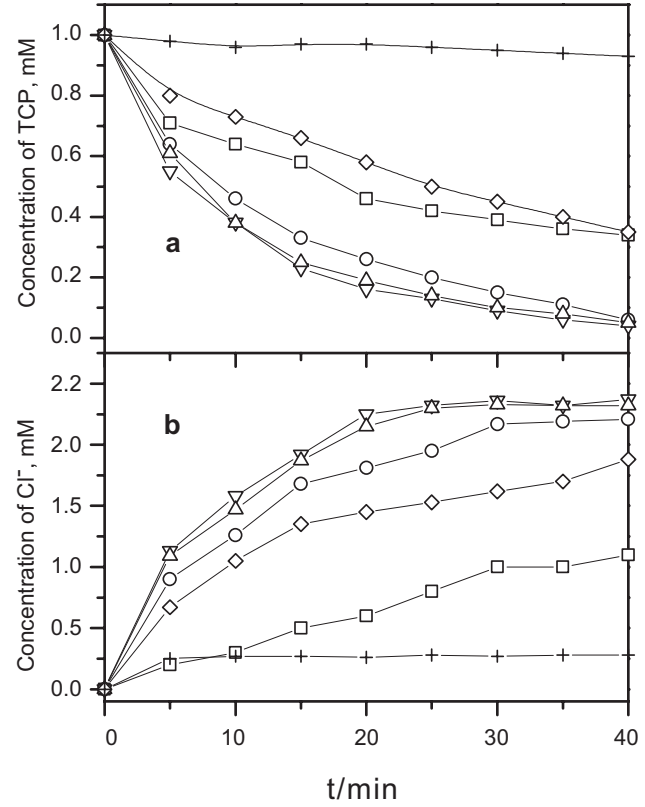

Fig. 4. The influence of $\mathrm{pH}$ on the degradation (a) and the dechlorination (b) of TCP. $[\mathrm{TCP}]_{0}=1 \mathrm{mM},\left[\mathrm{MoO}_{4}^{2-}\right]_{0}=2 \mathrm{mM}$, $\left[\mathrm{H}_{2} \mathrm{O}_{2}\right]_{0}=24 \mathrm{mM}, 25^{\circ} \mathrm{C} .(\square) \mathrm{pH}=8 ;(\bigcirc) \mathrm{pH}=9 ;(\triangle) \mathrm{pH}=10$; $(\nabla) \mathrm{pH}=11 ;(\diamond) \mathrm{pH}=12 ;(+) \mathrm{pH}=13$.

effect of $\mathrm{pH}$ on the degradation (Fig. 4a) and the dechlorination (Fig. 4b) of TCP. Good degradation efficiency could be obtained at the $\mathrm{pH}$ ranging from 9 to 11 . The degradation efficiency of TCP dropped dramatically on both sides of the optimal range. The loss of efficiency in the acidic solution is explained by the dissociation of TCP in solution, which has a $\mathrm{p} K_{\mathrm{a}}$ of 6.2. The first step of the TCP degradation is the oxidation of the phenolate anion, which presents in the acidic solution in a small amount, leading to the poor conversions. In very alkaline solutions ( $\mathrm{pH}>11), \mathrm{H}_{2} \mathrm{O}_{2}$ dissociates (Eq. (3)) and the equilibrium 1 is shifted to the left. Hence, no more peroxo complex formed, and the catalysis stopped (Aubry, 1988).

$\mathrm{H}_{2} \mathrm{O}_{2} \rightleftarrows \mathrm{H}^{+}+\mathrm{HO}_{2}^{-}$

\subsubsection{Effect of temperature}

The temperature effect on the degradation of TCP was also studied. The TCP solutions were incubated at different temperatures, namely, $15^{\circ} \mathrm{C}, 25^{\circ} \mathrm{C}, 35^{\circ} \mathrm{C}$, $45^{\circ} \mathrm{C}, 55^{\circ} \mathrm{C}, 65^{\circ} \mathrm{C}$, and $75^{\circ} \mathrm{C}$ for $10 \mathrm{~min}$. Then $\mathrm{MoO}_{4}^{2-}$ and $\mathrm{H}_{2} \mathrm{O}_{2}$ were added. Fig. 5 shows the effect of temperature on the degradation (Fig. 5a) and the dechlorination (Fig. 5b) of TCP. The degradation and dechlorination efficiency of TCP increased dramatically with the increase of the temperature. At $15^{\circ} \mathrm{C}$, only $65 \%$ TCP conversion was observed after $40 \mathrm{~min}$ reaction. At a 


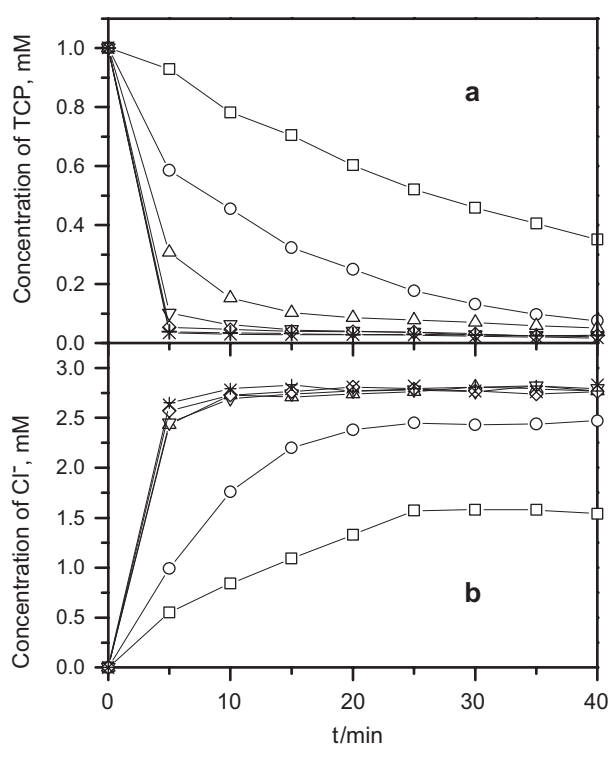

Fig. 5. The influence of temperature on the degradation (a) and the dechlorination (b) of TCP. $[\mathrm{TCP}]_{0}=1 \mathrm{mM}$, $\left[\mathrm{MoO}_{4}^{2-}\right]_{0}=2 \mathrm{mM},\left[\mathrm{H}_{2} \mathrm{O}_{2}\right]_{0}=24 \mathrm{mM}, \mathrm{pH}=10$. (口) $15^{\circ} \mathrm{C} ;(\mathrm{O})$ $25^{\circ} \mathrm{C} ;(\triangle) 35^{\circ} \mathrm{C} ;(\nabla) 45^{\circ} \mathrm{C} ;(\diamond) 55^{\circ} \mathrm{C} ;(\times) 65^{\circ} \mathrm{C} ;(+) 75^{\circ} \mathrm{C}$.

temperature above $25^{\circ} \mathrm{C}$, more than $95 \%$ of TCP could be degraded with about $2.4 \mathrm{Cl}^{-}$released per mol TCP in $20 \mathrm{~min}$.

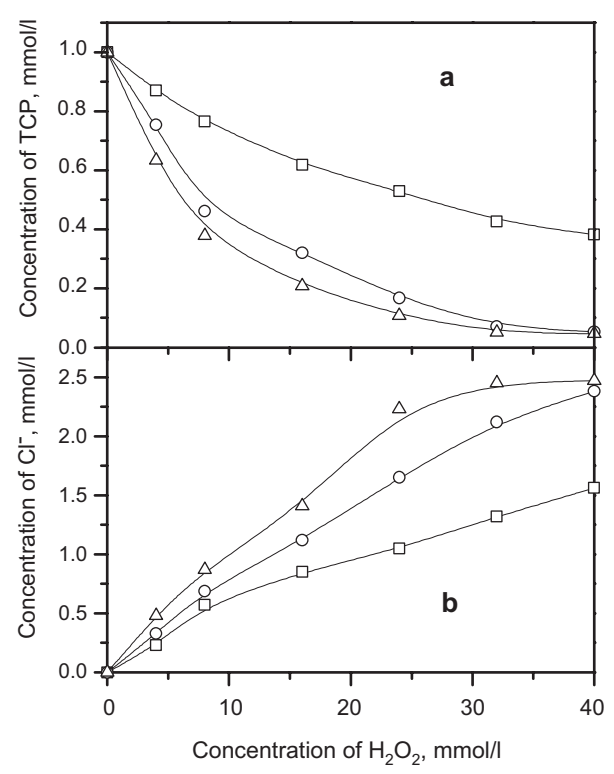

Fig. 6. The influence of $\mathrm{MoO}_{4}^{2-}$ and $\mathrm{H}_{2} \mathrm{O}_{2}$ concentration on the degradation (a) and the dechlorination (b) of TCP. $[\mathrm{TCP}]_{0}=1 \mathrm{mM},\left[\mathrm{H}_{2} \mathrm{O}_{2}\right]_{0}=24 \mathrm{mM}, \mathrm{pH}=10,25^{\circ} \mathrm{C}, 40 \mathrm{~min}$ reaction. ( $\square$ ) $0.5 \mathrm{mM} \mathrm{MoO}_{4}^{2-}$; (○) $1.0 \mathrm{mM} \mathrm{MoO}_{4}^{2-} ;(\triangle) 2.0 \mathrm{mM}$ $\mathrm{MoO}_{4}^{2-}$.

\subsubsection{Effect of $\mathrm{MoO}_{4}^{2-}$ and $\mathrm{H}_{2} \mathrm{O}_{2}$ concentration}

The influence of the $\mathrm{MoO}_{4}^{2-}$ and $\mathrm{H}_{2} \mathrm{O}_{2}$ concentration was studied at the pH 10 with a TCP concentration of $1 \mathrm{mM}$ at $25^{\circ} \mathrm{C}$. Fig. 6 shows the effect of $\mathrm{H}_{2} \mathrm{O}_{2}$ concentration on the degradation (Fig. 6a) and the dechlorination (Fig. 6b) of TCP with different $\mathrm{MoO}_{4}^{2-}$ concentration. As expected, the degradation and dechlorination efficiency of TCP increased dramatically with the increase of the $\mathrm{MoO}_{4}^{2-}$ and $\mathrm{H}_{2} \mathrm{O}_{2}$ concentration. This can be explained by the generation of singlet oxygen by $\mathrm{H}_{2} \mathrm{O}_{2} / \mathrm{MoO}_{4}^{2-}$ system, which is first order with respect to $\mathrm{MoO}_{4}^{2-}$ in the concentration range $0.2-2 \mathrm{mM}$ and second order with respect to $\mathrm{H}_{2} \mathrm{O}_{2}$ at concentrations less than $100 \mathrm{mM}$ (Aubry, 1988).

\section{Conclusion}

The dechlorination and destruction of 2,4,6-trichlorophenol (TCP) and pentachlorophenol (PCP) using hydrogen peroxide as the oxidant catalyzed by molybdate ions under weak basic condition were investigated. Different from the Fenton reaction, singlet oxygen was found to play an important role in the degradation of TCP and PCP. The $\mathrm{H}_{2} \mathrm{O}_{2} / \mathrm{MoO}_{4}^{2-}$ shows high activities under basic condition with $\mathrm{pH}$ range from 9 to 11 , while the Fenton reaction has high activities under acidic condition. Compare to the Fenton reaction, less catalyst (metal ions) but more oxidant (hydrogen peroxide) are needed in $\mathrm{H}_{2} \mathrm{O}_{2} / \mathrm{MoO}_{4}^{2-}$ system for the degradation of per TCP (Chu and Law, 2003). The degradation rate was strongly affected by many factors, such as the $\mathrm{pH}$ value, the temperature and the initial concentration of $\mathrm{H}_{2} \mathrm{O}_{2}$ and $\mathrm{MoO}_{4}^{2-}$.

\section{Acknowledgement}

This work was financially supported by the National Natural Science Foundation of China and the Chinese Academy of Sciences (20137010, KZCX2-414).

\section{References}

Almeida, E.A., Miyamoto, S., Martinez, G.R., Medeiros, M.H.G., Mascio, P.D., 2003. Direct evidence of singlet molecular oxygen $\left[\mathrm{O}_{2}\left({ }^{1} \Delta_{\mathrm{g}}\right)\right]$ production in the reaction of acetonitrile with hydrogen peroxide in alkaline solutions. Anal. Chim. Acta 482, 99-104.

Aubry, J.M., 1988. Chemical sources of singlet oxygen. 2. Quantitative generation of singlet oxygen from hydrogen peroxide disproportionation catalyzed by molybdate ions. Inorg. Chem. 27, 2013-2014.

Cheng, M., Ma, W., Li, J., Huang, Y., Zhao, J., 2004. Visiblelight-assisted degradation of dye pollutants over Fe(III)loaded resin in the presence of $\mathrm{H}_{2} \mathrm{O}_{2}$ at neutral $\mathrm{pH}$ values. Environ. Sci. Technol. 38, 1569-1575. 
Chu, W., Law, C.K., 2003. Treatment of trichlorophenol by catalytic oxidation process. Water Res. 37, 2339-2346.

Florence, T.M., Fanar, Y.J., 1971. Spectrophotometric determination of chloride at the parts-per-billion level by the mercury (II) thiocyanated method. Anal. Chim. Acta 54, 373-377.

Fufezan, C., Rutherford, A.W., Krieger-Liszkay, A., 2002. Singlet oxygen production in herbicide-treated photosystem II. FEBS Lett. 532, 407-410.

Fukushima, M., Tatsumi, K., 2001. Degradation pathways of pentachlorophenol by photo-Fenton systems in the presence of iron(iii), humic acid, and hydrogen peroxide. Environ. Sci. Technol. 35, 1771-1778.

Gabriel, J., Baldrian, P., Verma, P., Cajthaml, T., Merhautová, V., Eichlerová, I., Stoytchev, I., Trnka, T., Stopka, P., Nerud, F., 2004. Degradation of BTEX and PAHs by $\mathrm{Co}(\mathrm{II})$ and $\mathrm{Cu}(\mathrm{II})$-based radical-generating systems. Appl. Catal. B Environ. 51, 159-164.

Gallard, H., De Laat, J., 2001. Kinetics of oxidation of chlorobenzenes and phenyl-ureas by $\mathrm{Fe}(\mathrm{II}) / \mathrm{H}_{2} \mathrm{O}_{2}$ and $\mathrm{Fe}(\mathrm{III}) / \mathrm{H}_{2} \mathrm{O}_{2}$. Evidence of reduction and oxidation reactions of intermediates by $\mathrm{Fe}(\mathrm{II})$ or $\mathrm{Fe}(\mathrm{III})$. Chemosphere 42, 405-413.

Kang, N., Lee, D.S., Yoon, J., 2002. Kinetic modeling of Fenton oxidation of phenol and monochlorophenols. Chemosphere 47, 915-924.

Klein, S.M., Cohen, G., Cederbaum, A.R., 1981. Production of formaldehyde during metabolism of dimethyl sulfoxide by hydroxyl radical-generating systems. Biochemistry 20, 6006-6012.

Klibanov, A.M., Tu, T.M., 1983. Peroxidase-catalyzed removal of phenols from coal-conversion waste waters. Science 221, 259-261.

Kwon, B.G., Kang, N., Yoon, J., 1999. Characteristics of $p$ chlorophenol oxidation by Fenton's reagent. Water Res. 33, 2110-2118.

Lee, Y., Lee, C., Yoon, J., 2003. High temperature dependence of 2,4-dichlorophenoxyacetic acid degradation by $\mathrm{Fe}(\mathrm{III}) /$ $\mathrm{H}_{2} \mathrm{O}_{2}$ system. Chemosphere 51, 963-971.

Magar, V., Stgensel, H.D., Puhakka, J.A., Ferguson, J.F., 1999. Sequential anaerobic dechlorination of pentachlorophenol: competitive inhibition effects and a kinetic model. Environ. Sci. Technol. 33, 1604-1611.
Meunier, B., Sorokin, A., 1997. Oxidation of pollutants catalyzed by metallophtalocyanines. Acc. Chem. Res. 30, 470-476.

Nerud, F., Baldrian, P., Gabriel, J., Ogbeifun, D., 2001. Decolorization of synthetic dyes by the Fenton reagent and the $\mathrm{Cu} /$ pyridine $/ \mathrm{H}_{2} \mathrm{O}_{2}$ system. Chemosphere 44 , 957961.

Oliva-Teles, M.T., Paíga, P., Delerue-Matos, C.M., AlvimFerraz, M.C.M., 2002. Determination of free formaldehyde in foundry resins as its 2,4-dinitrophenylhydrazone by liquid chromatography. Anal. Chim. Acta 467, 97-103.

Piringer, G., Bhattacharya, S.K., 1999. Toxicity and fate of pentachlorophenol in anaerobic acidogenic systems. Water Res. 33, 2674-2682.

Ramamoorthy, S., 1997. Chlorinated Organic Compounds in The Environment. CRC Press, Boca Raton.

Salem, I.A., 2001. Activation of $\mathrm{H}_{2} \mathrm{O}_{2}$ by Amberlyst-15 resin supported with copper(II) complexes towards oxidation of crystal violet. Chemosphere 44, 1109-1119.

Sorokin, A., Seris, J.L., Meunier, B., 1995. Efficient oxidative dechlorination and aromatic ring cleavage of chlorinated phenol catalyzed by iron sulfophthalocyanine. Science 268, 1163-1166.

Sun, Y., Pignatello, J.J., 1992. Activation of hydrogen peroxide by iron(III) chelates for abiotic degradation of herbicides and insecticides in water. J. Agric. Food. Chem. 41, 308312.

Sun, Y., Pignatello, J.J., 1993. Chemical treatment of pesticide wastes. Evaluation of $\mathrm{Fe}$ (III) chelates for catalytic hydrogen peroxide oxidation of 2,4-D at circumneutral $\mathrm{pH}$. J. Agric. Food. Chem. 40, 322-327.

USEPA, 1991. Water quality criteria summary, ecological risk assessment branch (WH-585) and human risk assessment branch (WH-550D). Health and Ecological Criteria Division, USEPA, Washington, DC, USA.

Verma, P., Bvaldrian, P., Nerud, F., 2003. Decolorization of structurally different synthetic dyes using cobalt(II)/ascorbic acid/hydrogen peroxide system. Chemosphere 50, 975-979.

Xia, Q., Zhang, X.H., 1990. Manual on Water Quality Standards. Environmental Science Press, Beijing.

Ye, F.X., Shen, D.S., 2004. Acclimation of anaerobic sludge degrading chlorophenols and the biodegradation kinetics during acclimation period. Chemosphere 54, 1573-1580. 